\title{
Human eating behaviour in an evolutionary ecological context
}

\author{
Stanley J. Ulijaszek \\ Institute of Social and Cultural Anthropology, University of Oxford, 51 Banbury Road, Oxford OX2 6PE, UK
}

\begin{abstract}
Present-day human eating behaviour in industrialised society is characterised by the consumption of high-energy-density diets and often unstructured feeding patterns, largely uncoupled from seasonal cycles of food availability. Broadly similar patterns of feeding are found among advantaged groups in economically-emerging and developing nations. Such patterns of feeding are consistent with the evolutionary ecological understanding of feeding behaviour of hominids ancestral to humans, in that human feeding adaptations are likely to have arisen in the context of resource seasonality in which diet choice for energy-dense and palatable foods would have been selected by way of foraging strategies for the maximisation of energy intake. One hallmark trait of human feeding behaviour, complex control of food availability, emerged with Homo erectus $\left(1.9 \times 10^{6}-200000\right.$ years ago), who carried out this process by either increased meat eating or by cooking, or both. Another key trait of human eating behaviour is the symbolic use of food, which emerged with modern Homo sapiens (100 000 years ago to the present) between 25000 and 12 000 years ago. From this and subsequent social and economic transformations, including the origins of agriculture, humans have come to use food in increasingly elaborate symbolic ways, such that human eating has become increasingly structured socially and culturally in many different ways.
\end{abstract}

Feeding: Human evolution: Hominid diet: Energy

The study of human eating behaviour is carried out by researchers in various disciplines, since eating fulfils biological needs, but is also a source of pleasure and comfort, and reflects economic, social and cultural realities and perceptions (Mela, 1996). While clearly the biological drives of feeding, hunger and satiety have shared physiological bases with other mammals, including the primates, a central issue to the understanding of human eating is the characterisation of specific human feeding traits, which are novel or distinct from those of other mammals. Human ecological approaches can be helpful in such characterisations.

Much of the work on the ecology of human eating has focused on biological needs within economic, social and cultural frameworks (Pelto, 1987; Ulijaszek \& Strickland, 1993; de Garine, 1996; Wiessner, 1996), and the symbolic nature of specific foods and patterns of food consumption (Douglas, 1975; Fiddes, 1991). Humans raised within given cultural and social norms prefer customary foods and flavour combinations; however, within any socio-cultural context, different individuals may display varied likes and dislikes for particular foods (Douglas, 1978; Mela \& Catt, 1996). A problem, therefore, of understanding the ecology of human eating is how food preferences may have been shaped by evolution, are shaped in the shorter term, and can change within socio-cultural contexts.

The ecology of human eating must be considered in the context of human dietary change. A summary of the stages of evolution of human diets, modified from schemes put forward by Eaton \& Konner (1985) and Nestle (1999) is presented in Table 1. While Pleistocene diets are considered by both Eaton \& Konner (1985) and Nestle (1999) to represent the earliest stage of human diet, it is necessary to start further back in time than the Pleistocene to identify possible times of emergence of more uniquely human, or hominid, eating traits. This approach involves the use of an evolutionary ecology framework. Evolutionary ecology is the study of relationships between organisms and their environments, and the ways in which adaptive processes are central to the evolution of species (Foley, 1987). Evolution of diet in the context of changing foraging strategies of hominids ancestral to humans is fundamental to the understanding of the ecology of human eating behaviour. Behavioural ecology is a discipline that informs evolutionary ecology, and is a means of studying problem-solving 
and strategy as adaptive traits (Dunbar, 1993). With regard to feeding behaviour, optimisation of foraging activities and food choice to maximum gain is as subject to natural selection as are social organisation, reproductive behaviour, physiology and morphology (Foley, 1987). Cultural ecology was developed in attempts to separate human ecology from the ecology of other organisms (Ellen, 1982), and is important when analogy is used to try to understand the emergence of complex behaviour among the hominids. In this discipline the emphasis is on the ways in which cultural configurations emerge, change, reproduce and are sustained (Feld, 1996). A cultural ecology of eating behaviour should also examine the ways in which evolutionarily- and behaviourally-adaptive feeding traits may have become fixed, reproduced and sustained into the present day.

In the present article the human ecology of eating and energy balance is described, and the evolutionary and behavioural ecological bases of human eating traits are examined from an evolutionary perspective, using evidence from comparative primatology and hominid biology and ecology.

Table 1. Stages of evolution of human diets (adapted from Nestle, 1999; Eaton \& Konner, 1985)

\begin{tabular}{lc}
\hline & No of years ago \\
\hline Australopithecus & $4.4 \times 10^{6}$ \\
Homo & $2 \times 10^{6}$ \\
Homo sapiens: Archaic & 400000 \\
$\quad$ Neanderthal & 230000 \\
$\quad$ Modern & 100000 \\
Holocene: Agriculture & 12000 \\
$\quad$ Industrial revolution & 250 \\
Global food economy & 50 \\
\hline
\end{tabular}

\section{Human ecology of eating and energy balance}

Human eating provides dietary energy to fuel bodily maintenance, physical activity, growth and reproduction (Ulijaszek, 1992), and studies of energy balance among normal, undernourished and overnourished subjects have provided much of the empirical basis for the understanding of body-weight maintenance and change. Much of the literature on obesity and undernutrition among adults has focused on the maintenance of energy balance and the factors that lead to loss of balance, both short term and long term (Rothwell \& Stock, 1982; Waterlow, 1986; Shetty, 1993; Ulijaszek, 1996; Ralph \& James, 1999; Moore, 2000). Diet and physical activity are both strongly implicated in the regulation of body weight, with homeostatic physiological mechanisms defending the body against changes in energetics (Moore, 2000). Fig. 1 shows a scheme whereby energy balance may be maintained or challenged according to ecological circumstances. This scheme can be usefully considered in three categories, which in the real world flow into each other. These categories are human ecologies with: low food availability; high food availability; seasonal variation in food availability respectively. Physical and economic availability of food are very often primary determinants of quality and quantity of food eaten by humans (Mela, 1996), seasonal factors having bearing on both physical and economic availabilities.

In the case of absence of adequate food availability and/or high work load, physiological energy deficits may occur, resulting in weight loss (energy balance recalibrating at lower levels of intake and expenditure), with a range of physiological and behavioural nutritional adaptations (Ulijaszek, 1996) defending the body against energy deficits (Moore, 2000). In the presence of high food availability there are only very weak homeostatic mechanisms to restore energy balance in the face of energy surplus, and weight gain is easy. Weight loss in this context can only be achieved through strong cognitive control, since the physiological

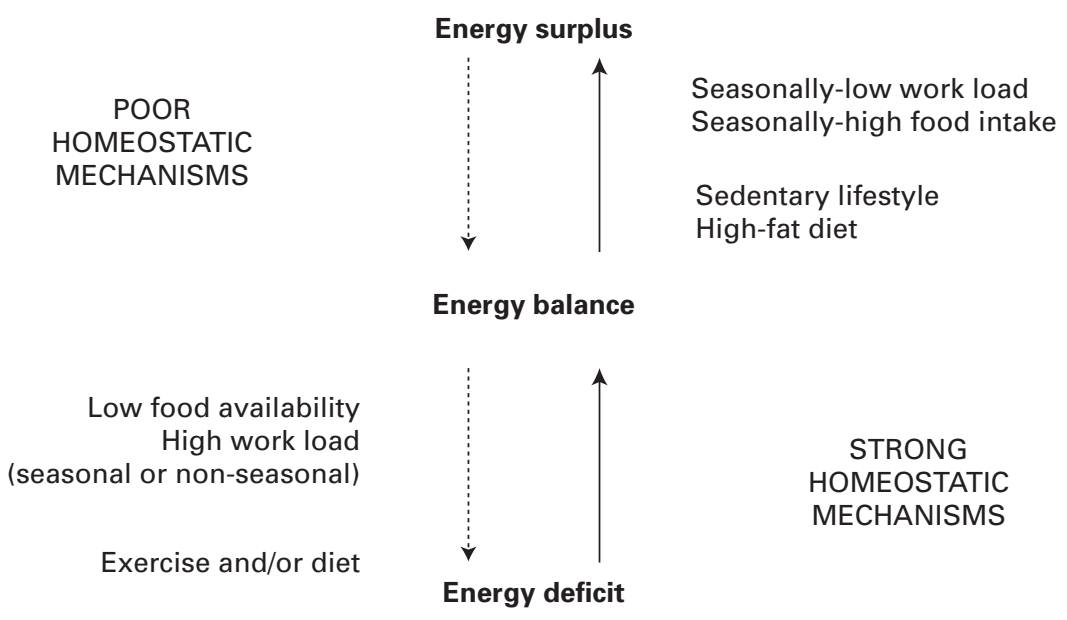

Fig. 1. Body-weight regulation. The three contexts of food availability are: low; seasonal; high. (Amended from Moore, 2000.) 
regulation of energy balance is easily overridden by psychological and behavioural factors that urge an individual to eat. In climatically-seasonal environments humans usually employ economic or socio-cultural avoidance strategies to buffer against body-weight fluctuation (Ulijaszek, 1995). However, there are many societies where such buffering is not possible. Ferro-Luzzi \& Branca (1993) have summarised seasonal weight change in adults from a number of populations in the rural developing world, and have concluded that weight loss rarely exceeds $5 \%$ of the seasonal high value, females experiencing smaller losses than males. Among agriculturalists, seasonal troughs in food availability often coincide with seasonal peaks in labour requirements (Ulijaszek, 1993), and vice versa, such that seasonal positive energy balance and weight gain is physiologically easy, while seasonal negative energy balance and weight loss is achieved by restricted food intake due to low food availability, but not strong cognitive control. Across evolutionary time, food availability would have been constrained by additional factors, including competition for the same resources from other species. Economic factors influencing food availability would have become important with emerging social and economic inequality after the origins of agriculture (Cohen, 1998), and have persisted, albeit in changing form, to the present day.

The mechanisms regulating short-term human eating behaviour are numerous and complex (French, 1999), involving the integration of positive drives to initiate and continue feeding from sensory cues, including sight, smell and palatability of food, with negative feedback signals arising from learned associations and gastrointestinal and metabolic signals (Blundell \& Greenough, 1994). Human eating behaviour involves learning, since there are few unlearned sensory likes among humans (Mela \& Catt, 1996); it has also a high extent of stability, but eating decisions are heavily determined by the social context of eating, and the expectations from foods before eating (Mela, 1996). In the absence of food limitation, one of the most powerful influences on the amount of food eaten by humans in one meal is the influence of other individuals at the meal (de Castro, 1999), the more individuals present, the more being eaten (de Castro, 1990, 1994). The evolutionary ecological bases for some aspects of social feeding are likely to lie deeper in the evolutionary past than with hominid evolution, given the extent to which it is found in different animal species. Human diet has a high energy density relative to other primate species, and it has been conjectured that this factor reflects an adaptation across evolutionary time to the high metabolic costs of large brain size (Martin, 1993). Encephalisation among the hominids may have conferred selective advantage from closelyrelated social and ecological pressures (Foley \& Lee, 1991). Diet change among the hominids, associated both with encephalisation and changing social complexity (Foley \& Lee, 1991), would have taken place under conditions of varying food resource availability and would have facilitated the emergence of social feeding, as well as the tendency to over-consumption when possible. Social feeding may have been a behavioural adaptation of early Homo that has continued to have implications for energy balance of contemporary human populations. In the present day, the tendency to over-consumption may continue to be of adaptive value to primate species and human populations in the rural developing world living in seasonal environments.

Another important factor influencing the amounts of food eaten when there is adequate food availability is palatability (Spitzer \& Rodin, 1981). Food palatability is associated with complex relationships between unlearned and learned sensory responses to foods, and conditioned preferences for taste and odour (Mela \& Catt, 1996). Flavour preferences in human subjects are influenced by the energy content of foods, as either fat or carbohydrate (Booth et al. 1982); there is a clear preference for foods associated with fat or sugar among both children (Mela \& Catt, 1996) and adults (Drewnowski \& Greenwood, 1983). Palatability of diet is perhaps less important as a factor in eating and energy balance when food availability is low. However, it is of fundamental importance when considering how diet choice may have been constructed over evolutionary time, as well as more recently, since the origins of agriculture about 12000 years ago, and the emergence of industrial society about 250 years ago.

One theory of food over-consumption in human subjects is that of poor restraint; obese subjects are more likely to practise unrestrained eating, with lack of slowing of eating rate across the course of a meal than lean subjects (Herman \& Mack, 1975). An alternative theory, that of externality, postulates that obese subjects are more reactive to external cues, such as the time of day, presence of food and situational effects, and less sensitive to internal physiological hunger and satiety signals than are lean subjects (Schachter, 1971; Schachter \& Rodin, 1974). According to this view, high reactivity to external cues encourages overeating and the development of obesity in environments in which highly-palatable food is readily available.

The energy density of food has also been shown to be strongly related to level of food intake (Stubbs, 1998), while passive over-consumption of fat in high-fat diets has been linked with poor metabolic compensation of positive energy balance (Blundell \& Stubbs, 1997). If individuals eat to a constant volume or weight of food (Poppitt \& Prentice, 1996; Rolls et al. 1998), then passive over-consumption is less likely on diets with low energy density. The possibility of over-consumption among past populations would then have depended on the energy density of the diet, which would have varied enormously according to ecological circumstances, ranging from high values among some hunter-gatherer groups (Speth, 1991), to low values among many agriculturalists (Ulijaszek, 1991). Seasonal overconsumption occurs in most kinds of subsistence economy (Benefice et al. 1984; Dugdale \& Payne, 1986; de Garine \& Koppert, 1988; Galvin et al. 1994).

However, given that seasonality is a fundamental environmental factor in mammalian, and primate (Hladik, 1988) ecology, and hominid evolution (Foley, 1993), the material and psychological bases for over-consumption, passive or otherwise, may have been selected at some stage of mammalian evolution. The knowledge that a 'cafeteria diet', consisting of highly-palatable foods, such as biscuits, cake, chocolate, butter, pate, bacon, bread, corned beef and pasta, can induce hyperphagia and dramatic weight gain in adult 
rats (Rothwell \& Stock, 1982) suggests that the tendency to over-consumption is more a general mammalian evolutionary trait than a more specific primate or hominid evolutionary trait. The tendency to over-consumption in the face of plentiful food availability may well have been of selective value to both ancestral hominids and ancestral primate species living in seasonal environments.

\section{Human evolutionary perspectives on eating}

Animal feeding behaviour has been described by Kyriazakis et al. (1999) as a continuous close-looped system, whereby food intake and diet selection influence, and in turn are influenced by, an animal's internal state and knowledge of its feeding environment. The internal state changes as a direct consequence of feeding (or lack of it) or other stimuli. It also changes as a consequence of longer-term physiological changes across the lifespan (Kyriazakis et al. 1999). With regard to long-term changes, the extent of developmental maturity (Bradford \& Gous, 1991; Kyriazakis et al. 1993) and pregnancy and lactation (Cooper et al. 1994) influence the diet choice of pigs and sheep.

Models of feeding regulation of mammals other than man have been put forward, which theorise that: (1) animals eat to meet their nutritional requirements subject to physical constraints, including food availability (Emmans \& Oldham, 1988); (2) there is no strict control from any major physiological pathway of desire to eat in relation to nutritional requirement, or environmental constraint of intake through availability, but that intake is regulated by a milieu of physiological signals each with different costs and benefits (Ellis et al. 1999).

Fig. 2 shows feedback relationships between animal physiology and genotype, food and environment that underpin the 'eating to meet requirements subject to constraints' theory first put forward by Adolph (1947) and modified by Emmans \& Oldham (1988). While this model has been modified in the case of ruminants (Forbes, 1996; Illius \& Jessup, 1996; Ellis et al. 1999) and herbivores (Pitroff \& Kothmann, 1999), it may remain valid for nonruminant species, including the primates. Animals need resources from food to maintain themselves, grow and reproduce; in general, animals eat to meet their physiological requirements and needs for physical activity, subject to environmental food availability constraints (Emmans \& Kyriazakis, 2001).

The ease with which unrestrained feeding can be induced across a number of mammalian species suggests that poor restraint may be a more general pan-mammalian characteristic, with perhaps obese subjects lying at one end of a distribution for potential for unrestrained feeding among humans in which few individuals have low potential. With regard to externality, the relationship with overweight is more complex than originally proposed (Spitzer \& Rodin, 1981; Mela, 1996), but the suggestion that externality may be an antecedent of obesity and not a consequence or correlate of overeating (Mela, 1996) indicates that one key to understanding the evolutionary basis of overeating in humans lies with the study of primate and hominid sociality.

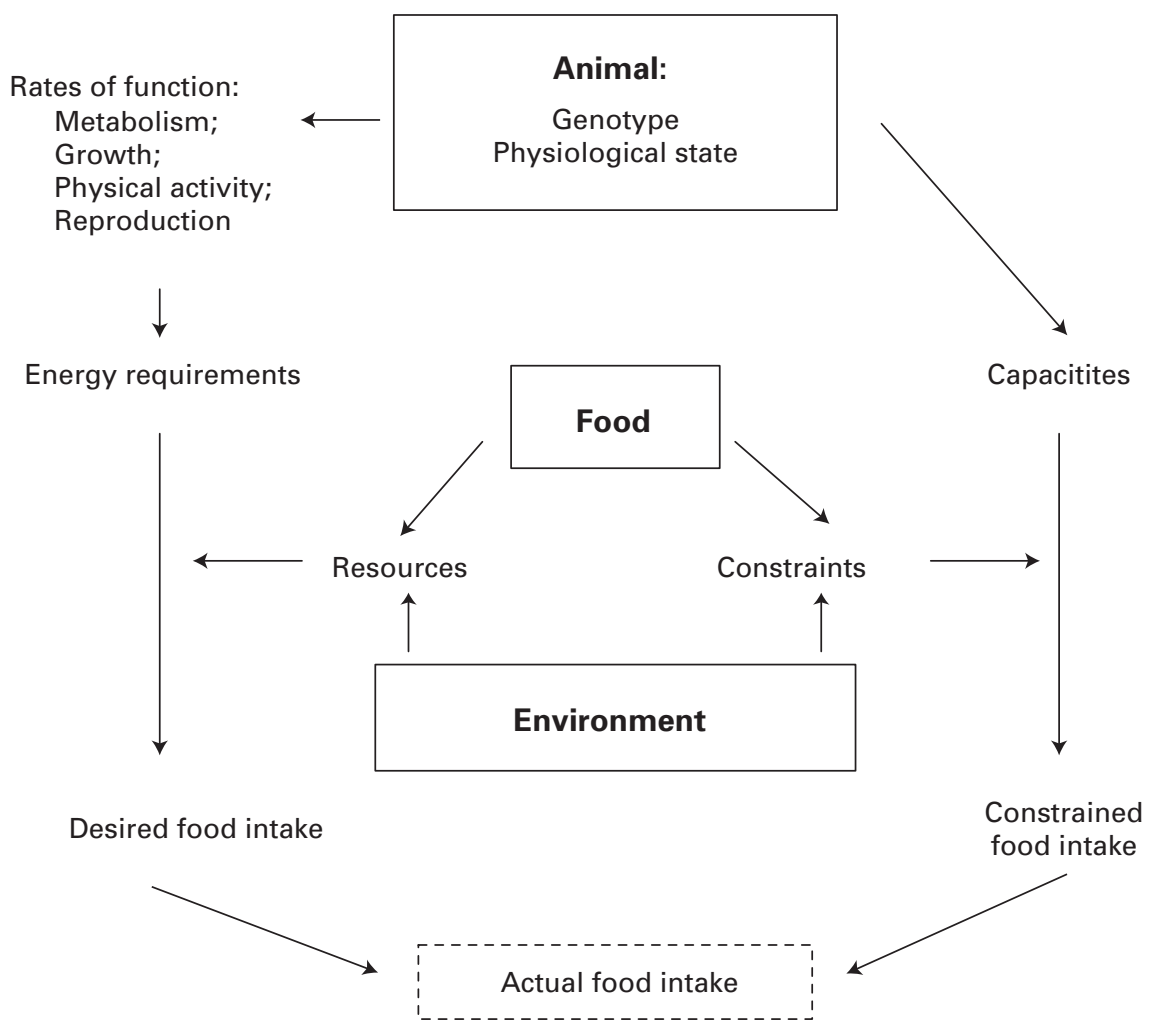

Fig. 2. Animal feeding and internal state. (Adapted from Emmans \& Oldman, 1988.) 


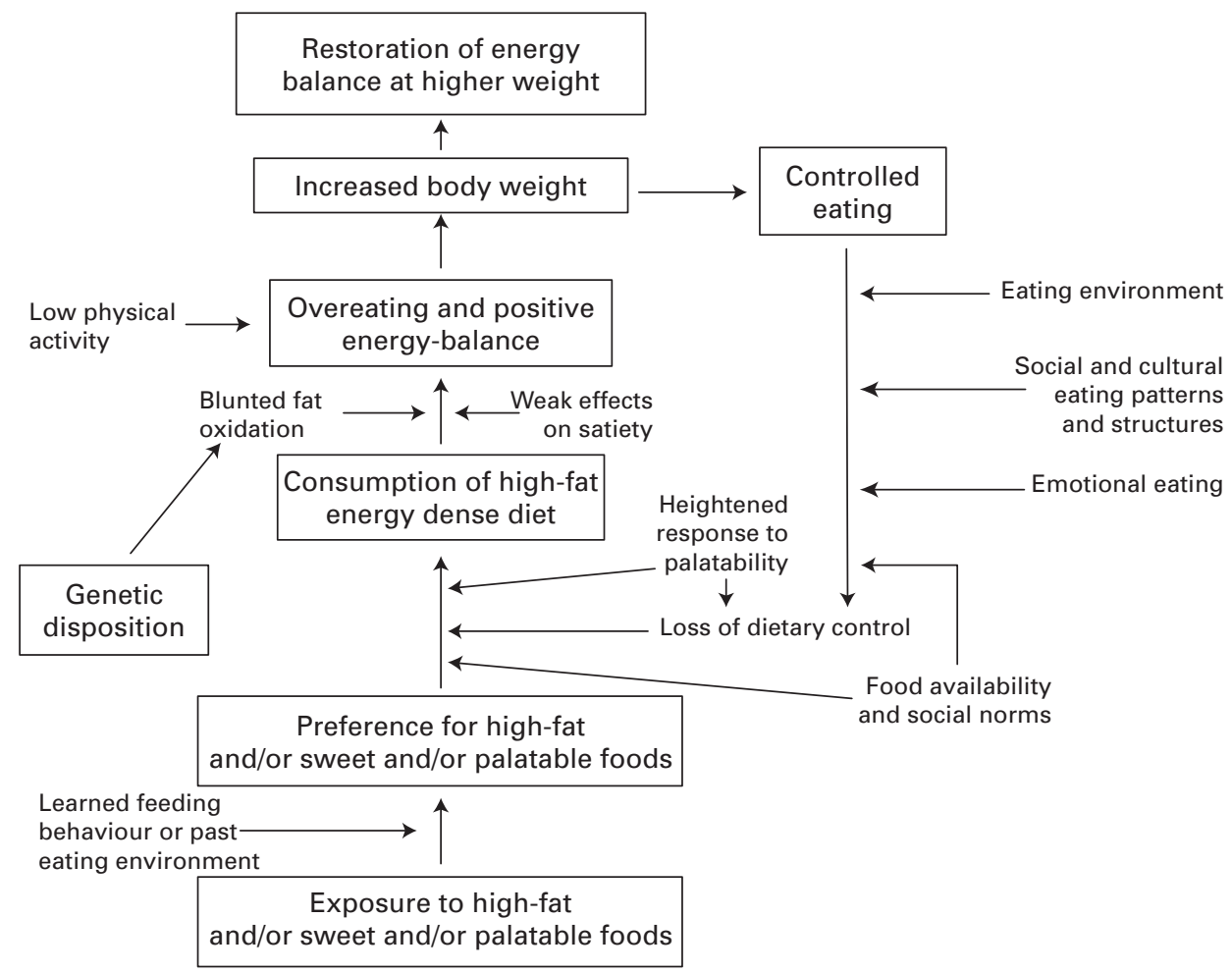

Fig. 3. Human eating behaviour and fatness. (Modified from Mela, 1996.)

What distinguishes human eating from mammalian feeding is the extent to which personal and psychological constraints may operate in addition to food availability constraints, and the ease with which consumption can exceed physiological requirements when there are few environmental food availability constraints. Fig. 3 shows a mechanism modified from Mela (1996) whereby human body-weight homeostasis may be maintained or lost, subject to a range of factors including food availability, energy density of the diet, genetic, psychological, physiological, behavioural and cultural factors. What is notable about this model is the extent to which cultural, social and psychological factors come to bear on eating patterns and energy balance in humans. There is considerable difference in complexity between the model of mammalian feeding shown in Fig. 2 and the model of human eating given in Fig 3. The next section examines possible evolutionary bases for these differences.

\section{Transition from mammalian feeding to human patterns of eating}

\section{Evidence from comparative primatology}

Primates are essentially fruit-eaters (frugivores), with guts showing proportions intermediate between the dominating small intestines of meat-eaters (faunivores) and the much enlarged stomach or caecum and colon of leaf-eaters (folivores; Chivers, 1993). This characteristic gives them unique dietary flexibility, such that smaller primates can supplement fruit with animal matter, and larger species have some folivorous adaptations. All primates show considerable dietary variation across the year, especially in areas with marked seasonality (Chivers, 1993; Fleagle, 1999). Humans are broadly similar to other primate species in that they are omnivorous, with nutritional requirements that reflect adaptations to diets high in fruit and vegetation (Leonard, 2000). However, human diets have greater energy density than those of other primates of similar body size (Leonard \& Robertson, 1994), given that BMR scales allometrically with body size, such that basal energy requirements are lower per unit body size for larger mammals than smaller ones (Brody, 1945).

Among primates, food selection is highly developed, with taste, vision and smell all used to discriminate appropriate from inappropriate potential food items. Among frugivorous primates there are high rates of discard for fruit that is either unripe or too ripe, while there is a strong preference for immature leaves among folivorous primates (Dunbar, 1988; Richard, 1993). There is, therefore, a preference for palatable food items among the primates, which might be related to taste sensitivity. Among the simian primates, the number of taste buds is greater among species with larger body size than those with smaller body size (Machida et al. 1967), suggesting greater potential for taste discrimination among primates with larger body size (Simmen \& Hladik, 1998). Furthermore, larger primates have lower sucrose taste sensitivities than smaller ones (Simmen \& Hladik, 1998; Fig. 4), the scaling of these taste thresholds with regard to body weight perhaps having important implications for the feeding strategies that different species adopt. BMR per unit body mass scales negatively with body weight among primates (Martin, 


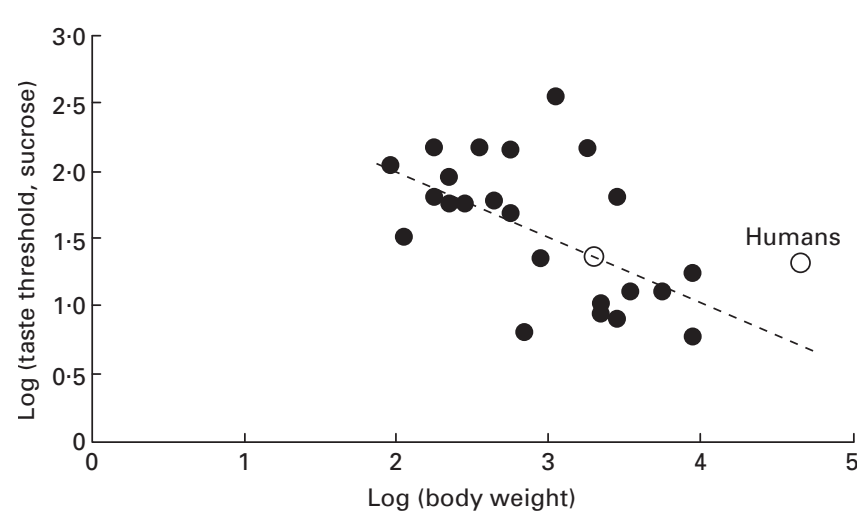

Fig. 4. Taste threshold for sucrose $v$. body weight for primates $(\bullet)$. (O), Humans. $r-0.53, F 11.4, P<0.01$. (Modified from Simmen \& Hladik, 1998.)

1993), making the energy requirement per unit body size lower in large primates than in small ones. This factor allows larger primates to use a wider variety of food sources with different energy densities than smaller primates. In addition, low sweetness and bitterness sensitivities allow larger primate species to find palatable food and select sources of lower energy density than small primate species. Humans also have low sucrose taste sensitivities, characteristics that are likely to have been extant throughout hominid evolution, and which would probably have influenced food selection. However, unlike other large apes, humans have maintained high diet breadth along with increased diet quality.

Simmen \& Hladik (1998) have proposed a model for the evolution of sweet taste discrimination in primates. The ability of early small insectivores and frugivores to taste sugars may have evolved primarily as an adaptive process favouring the occupation of frugivorous-nectivorous niches in the context of flowering plant diversification, and may have been close to that of extant prosimianians such as Microcebus. Sweet taste discrimination was improved in relation to changes in energy needs to allow larger species to increase the range of potentially-edible foods, and in some cases was little modified from that of ancestors that were probably frugivores. This form of diversification may still play a role in primate feeding behaviour, particularly in respect of the maintenance of behavioural flexibility to environmental contingencies.

Diet choice for foods that have the greatest bioavailability of dietary energy is likely to have been selected for by way of foraging strategies that optimise time-space use for the maximisation of energy intake in seasonal environments. Marked shifts in the diets of primates in response to the seasonal availability of preferred foods has been described for various primate species (Dunbar, 1988). Hominid food selection and eating behaviour is likely to have evolved from this broad context.

The level of dietary constraint across hominid evolution is far from certain, although it is likely to have varied enormously. Mori (1979) demonstrated that macaques (Macaca spp.) spend much longer foraging and lose weight when moved to a diet consisting entirely of leaves, but gain weight and spend much less time foraging daily when moved to a diet consisting of wheat, suggesting that internal state and feeding are closely tied in this species. Furthermore, primates often forage more efficiently in groups, and may congregate in large numbers where food sources are good (Dunbar, 1988). Although the basis for this behaviour may be defence and/or monitoring of resources (Dunbar, 1988), such primate social feeding is more complex than more general mammalian social feeding, in that it forms the basis of a large proportion of all feeding and foraging activity, and may be the basis of social feeding among the hominids, humans among them. It may also be the basis of externality of feeding, which would have carried selective advantage under conditions of resource constraint, as may have been the case among primate species in the past.

\section{Evidence from hominid evolutionary ecology}

There are two key features of human eating behaviour that are not shared with animals on any appreciable scale: complex control of food availability; the maintenance of complex social and cultural norms of diet and eating. In order to place these issues more firmly in the context of hominid evolution, it is important to have some understanding of the various hominid taxa and their feeding adaptations. Hominid taxa established from fossil evidence and phylogenetic analysis are given in Table 2 . This scheme is tentative, since there continues to be much debate over hominid classification. There are two principal reasons for this debate. First, the fossil record is incomplete, and the finding of new specimens will allow reinterpretation of the entire fossil record as known at any given time. Second, assignation to taxa according to morphological criteria can be carried out at coarser or finer levels of anatomical interpretation, giving fewer or greater numbers of species according to the measurements and assumptions underlying analysis (Foley, 1995). The descriptions of hominid ecology that follow are based on taxonomic classifications put forward by Wood (1994), Wood \& Collard (1999), Asfaw et al. (1999) and Carretero et al. (1999).

Climatic cooling during Late Miocene $\left(6 \cdot 0-5 \cdot 3 \times 10^{6}\right.$ years ago) probably triggered ecological change that led to speciation of the super-family Hominoidea into the family Hominidea, along with other mammalian speciations. The one transitional fossil between the hominoids and the hominids is that of Ardipithecus ramidus, found in Ethiopia in 1994 (White et al. 1994).

Table 2. Hominid taxa from fossil evidence (from Wood, 1994; Asfaw et al. 1999; Carretero et al. 1999; Wood \& Collard, 1999)

\begin{tabular}{lll}
\hline Australopithecus & Paranthropus & Homo \\
\hline A. ramidus & P. aethiopicus & H. rudolfensis \\
A. anamensis & P. boisei & H. habilis \\
A. afarensis & P. robustus & H. ergaster \\
A. africanus & & H. erectus \\
& & H. antecessor \\
& H. heidelbergensis \\
& H. neanderthalensis \\
& H. sapiens \\
\hline
\end{tabular}


The genus Australopithecus existed in Africa between 4.4 and $2.5 \times 10^{6}$ years ago, and included the species $A$. ramidus (4.4-4.2 $\times 10^{6}$ years ago), A. anamensis $\left(4 \cdot 2-3.5 \times 10^{6}\right.$ years ago), A. afarensis (3.8-3.0 $\times 10^{6}$ years ago) and A. africanus $\left(2 \cdot 8-2 \cdot 2 \times 10^{6}\right.$ years ago). These species were bipedal, with tree-climbing abilities. In general, the australopithecines had large molars, indicative of an almost exclusively vegetarian diet. The genus Paranthropus was formerly classified as part of the genus Australopithecus, and comprises what were previously considered to be the skeletally-robust forms of the genus Australopithecus. Very large molar teeth and jaw muscles indicate that they had vegetarian diets comprising largely of coarse plant material. The three Paranthropus species identified include $P$. aethiopicus $\left(2.5-1.9 \times 10^{6}\right.$ years ago), $P$. boisei $\left(2 \cdot 1-1 \cdot 2 \times 10^{6}\right.$ years ago), and $P$. robustus $\left(1.8-1.0 \times 10^{6}\right.$ years ago $)$.

Early Homo probably evolved from one of the australopithecines, possibly about $2.4 \times 10^{6}$ years ago, but certainly by $2 \times 10^{6}$ years ago. What distinguished them from the australopithecines was larger brain size, and very clear bipedal anatomy lacking arboreal adaptations. They had smaller teeth, with thinner enamel than the australopithecines, suggesting a diet that contained more higherquality foods, including meat. The following Homo taxa have been identified: $H$. rudolfensis $\left(2.4-1.8 \times 10^{6}\right.$ years ago), $H$. habilis $\left(1.8-1.5 \times 10^{6}\right.$ years ago), $H$. ergaster $\left(1.8-1.2 \times 10^{6}\right.$ years ago $), H$. erectus $\left(1.9 \times 10^{6}-200000\right.$ years ago), $H$. antecessor (800 000 years ago), $H$. heidelbergensis (500 000-200 000 years ago), H. neandertalensis (or $H$. sapiens neanderthalensis; 230 000-29000 years ago), and $H$. sapiens (or Homo sapiens sapiens; Archaic form 400 000-50 000 years ago; Modern 100000 years ago to the present). The phylogenetic relationship of the neanderthals to humans remains an issue of debate, some scholars placing both within the species $H$. sapiens, other scholars giving them separate species assignations (Stringer, 1993; Lewin, 1998). Hereafter in the present article, the two forms are referred to as $H$. sapiens and $H$. neanderthalensis, acknowledging that the alternative classifications $H$. sapiens sapiens and $H$. sapiens neanderthalensis may be equally valid.

\section{Hominid diet}

There are clear accounts of the possible dietary characteristics of hominids ancestral to $H$. sapiens. Morphological characteristics of the dentition of fossil hominids have been used to derive a number of hypothetical dietary patterns, the general consensus being of a diverse largely vegetarian diet in the australopithecines. With the emergence of early Homo from about $1.8 \times 10^{6}$ years ago, there is conjectured to have been considerable exploitation of meat (Isaac \& Crader, 1981), predominantly by scavenging (Blumenschine, 1991) in association with the development of stone tools (Isaac, 1983), and the maintenance of dietary diversity despite the increased body size that characterises the transition from Australopithecus to $H$. erectus. This feeding adaptation is likely to have arisen in the context of resource seasonality (Foley, 1993).

Meat eating among early Homo is most likely to have come from catchement scavenging (H. rudolfensis,
$H$. habilis and $H$. erectus) and territory scavenging $(H$. ergaster $)$. Evidence of group hunting of large game appeared with $H$. heidelbergensis, and became elaborated with $H$. neandertalensis, who were social hunter-gatherers, practising cooperative hunting. H. sapiens was also a hunter-gatherer, but able to forage at levels of complexity that far outstripped all other species of Homo.

Homo sapiens was capable of language, and symbolism, and possessed similar stone tool technologies to those of $H$. neanderthalensis, which in both cases were more complex than those used by earlier Homo species (H. habilis, H. ergaster, H. erectus, $H$. heidelbergensis). About 40000 years ago, tool use and other technologies were elaborated to new levels of complexity by $H$. sapiens. Bone and antler tools, such as spear tips and harpoons first appear in the archaeological record around 40000 years ago, and there is evidence to suggest that animal traps, bows and arrows were used subsequent to this time. Hafts and handles for knives were also developed, blades being secured with bitumen. Other improvements included the invention of the atlatl, a large bone or piece of wood with a hooked grove used for adding distance and speed to spears, and the development of more sophisticated spear points, such as those that detach after striking, thus causing greater damage to prey. They were nomadic hunter-gatherers, with detailed environmental knowledge, including seasonal variation, with the marking of time according to lunar phases by making 'calendar' markings on bone, antler or stone.

Complex control of food availability could not occur before the greater brain and body size, decreased arboreal adaptation and anatomical commitment to bipedalism and prolonged bouts of physical activity in open and arid environments that characterised $H$. erectus (Wrangham et al. 1998) and possibly $H$. ergaster. With $H$. erectus, total energy expenditure increased by between 40 and $85 \%$ over australopithecine values (Leonard \& Robertson, 1997), as a result of both increased body size and increased physical activity schedules. Large body size with increasingly complex behaviour would have enabled increased home range, greater dominance of the food chain and increased dietary energy capture and intake, without decrease in dietary quality (Milton, 1987). The predominant hypothesis for the great dietary change observed to have taken place with the evolution of early Homo is an increase in meateating taking place at the time of ecological change in Africa, associated with global cooling that started about $2.5 \times 10^{6}$ years ago (Leonard \& Robertson, 1994). There was a dramatic increase in the amount of open grassland environments in Africa that would have influenced the density and distribution of high-quality plant foods for animal consumption, which would in turn have made animals an increasingly attractive food resource for hominids (Vrba, 1988). All subsequent hominids (H. heidelbergensis, $H$. neanderthalensis, $H$. sapiens, and possibly also $H$. antecessor) also maintained control of the food supply by way of complex foraging strategies. An alternative and more speculative hypothesis has been put forward by Wrangham et al. (1998), who interpreted the smaller dentition and larger female body size of $H$. erectus as being an outcome of the control of fire in Africa $1.6 \times 10^{6}$ years ago (Bellomo, 1994). Initially, this development was for protection, but 
also for cooking thereafter, which would have had widespread effects on nutrition, ecology and social relationships, even in the absence of increased meat consumption. Both hypotheses involve increased complexity of food availability control, one through increased meat capture without substitution of vegetational dietary sources, the other through increased bioavailability of existing food resources.

Social and cultural norms of diet and eating are likely to have increased in complexity at a later stage of hominid evolution, with the emergence of complex symbolic behaviour among $H$. sapiens and $H$. neanderthalensis. Both species had more complex toolkits than early Homo. However, by 25000 to 15000 years ago, tool industries of $H$. sapiens diversified, with the generation of specialised tools for the hunting of different types of medium-sized mammals, including reindeer (Rangifer tarandus) and horse (Equus caballus), with the domestication of animals starting by about 15000 years ago. $H$. sapiens was able to consume a diet of greater quality and diversity than any other hominid species, and the symbolic representation and use of food is likely to have become elaborated across the period 25000 12000 years ago.

While there is no direct evidence of this symbolism in the archaeological record, there is clear evidence of increased ritualisation of life in general across this period. While $H$. neanderthalensis are known to have buried their dead in perhaps ritualised manner (Lewin, 1998), $H$. sapiens increased the ritualisation of death and burial, with symbolic representation by personal adornment in burial becoming more common. There is extremely limited evidence that $H$. neanderthalensis made art, the only known art object attributable to neanderthals being a single carved and polished baby mammoth tooth, veined with red ochre, dated to between 80000 and 100000 years ago. $H$. sapiens, on the other hand, left extensive works of art, such as cave paintings and carved figures of animals and pregnant women. These artefacts are strong evidence of symbolic and abstract thinking among $H$. sapiens. One component of such thinking may have been food symbolism, possibly within early religious frameworks, in which meat symbolism may have been particularly important, given the importance of hunting and consumption of meat to $H$. sapiens at this time (Shipman, 1983). Certainly, meat symbolism has become elaborated in both religious and secular contexts into the present day (Fiddes, 1991). In addition to possibly increasing food availability by increasing bioavailability of nutrients for $H$. erectus (Wrangham et al. 1998) and for the later hominids who were also able to harness fire to their own use, cooking allowed the cultural elaboration of food, and an increase in the potential symbolic power of foods in social transactions and in forging and maintaining individual and group identity. Levi-Strauss (1970) underscored the notion of cooking as the fundamental articulation of the distinction between nature and culture, and as being one way in which humans conceive themselves as being different from the rest of the animal world. If Wrangham et al. (1998) are correct, then it might be that cooking served the same symbolic function for $H$. erectus; as an act that differentiated them from the rest of nature.

\section{Conclusions}

Human feeding patterns clearly differ from those of other mammalian species in the complexity of behaviours associated with feeding. While human social feeding, externality of feeding, preference for palatable foods and potential for over-feeding clearly have their parallels in the animal world, there are differences in complexity in these characteristics that emerged in the course of primate and hominid evolution. There are two features of human eating behaviour that are not shared with animals on any appreciable scale, these features being the complex control of food availability, and the maintenance of complex social and cultural norms of diet and eating. Both these features are most likely to have arisen in the course of hominid evolution, the former with the emergence of $H$. erectus and possibily also $H$. ergaster, the latter with the emergence of $H$. neanderthalensis and, most importantly, H. sapiens. The larger body size and increasingly complex behaviour of $H$. erectus, as compared with australopithecines, would have enabled $H$. erectus to have a greater home range and increased dominance of the food chain, with increased dietary energy capture and intake without decrease in dietary quality. The period 25 000-15 000 years ago saw enormous diversification of the tool industries of $H$. sapiens, with the proliferation of increasingly symbolic material culture and art, indicating increasing ritualisation of everyday life. Modern $H$. sapiens was able to consume a diet of greater quality and diversity than any other hominid species before it, and it is likely that the symbolic representation and use of food was elaborated at this time. Subsequently, social and cultural norms of eating are likely to have diversified in the context of ecological change, human migration, and the emergence of agriculture, and the development of socially- and economically-stratified societies (Cohen, 1998). Further elaboration would have taken place in the wake of new economic structures that underpinned agricultural and urban societies; the rest is history.

\section{References}

Adolph EF (1947) Urges to eat and drink in the rat. American Journal of Physiology 151, 110-125.

Asfaw B, White T, Lovejoy O, Latimer B, Simpson S \& Suwa G (1999) Australopihecus garhi: a new species of early hominid from Ethiopia. Science 284, 629-635.

Bellomo RV (1994) Identifying traces of natural and humanlycontrolled fire in the archaeological record: The role of actualistic studies. Archaeology in Montana, Butte 32, 75-93.

Benefice E, Chevassus-Agnes S \& Barral H (1984) Nutritional situation and seasonal variations for pastoral populations of the Sahel (Senegalese Ferlo). Ecology of Food and Nutrition 14, 229-247.

Blumenschine RJ (1991) Hominid carnivory and foraging strategies, and the socio-economic function of early archaeological sites. Philosophical Transactions of the Royal Society of London 334B, 211-221.

Blundell JE \& Greenough A (1994) Pharmocological aspects of appetite: implications for the treatment of obesity. Biomedicine and Pharmacotherapy 48, 119-125.

Blundell JE \& Stubbs J (1997) Diet composition and the control of food intake in humans. In Handbook of Obesity, pp. 243-272 
[GA Bray, C Bouchard and WPT James, editors]. New York: Marcel Dekker Inc.

Booth D, Mather P \& Fuller J (1982) Starch content of ordinary foods associatively conditions human appetite and satiation, indexed by intake and eating pleasantness of starch-paired flavours. Journal for Intake Research 3, 163-184.

Bradford MMV \& Gous RM (1991) The response of growing pigs to a choice of diets differing in protein content. Animal Production 52, 185-192.

Brody S (1945) Bioenergetics and Growth. New York: Reinhold.

Carretero JM, Lorenzo C \& Arsuaga JL (1999) Axial and appendicular skeleton of Homo antecessor. Journal of Human Evolution 37, 459-499.

Chivers DJ (1993) Diet and guts. In The Cambridge Encyclopedia of Human Evolution, pp. 60-64 [S Jones, R Martin and D Pilbeam, editors]. Cambridge: Cambridge University Press.

Cohen NM (1998) The emergence of health and social inequalities in the archaeological record. In Human Biology and Social Inequality, pp. 249-271 [SS Strickland and PS Shetty, editors]. Cambridge: Cambridge University Press.

Cooper SDB, Kyriazakis I \& Oldham JD (1994) The effect of late pregnancy on the diet selection made by ewes. Livestock Production Science 40, 263-275.

de Castro JM (1990) Social facilitation of duration and size but not rate of the spontaneous meal intake of humans. Physiology and Behavior 47, 1129-1135.

de Castro JM (1994) Family and friends produce greater social facilitation of food intake than other companions. Physiology and Behavior 56, 445-455.

de Castro JM (1999) What are the major correlates of macronutrient selection in Western populations? Proceedings of the Nutrition Society 58, 755-763.

de Garine I (1996) Food and the status quest in five African cultures.In Food and the Status Quest, pp. 193-217 [P Wiessner and W Schieffenhovel, editors]. Oxford: Berghahn Books.

de Garine I \& Koppert G (1988) Coping with seasonal fluctuations in food supply among savanna populations: the Massa and Mussey of Chad and Cameroon. In Coping with Uncertainty in Food Supply, pp. 210-259 [I de Garine and GA Harrison, editors]. Oxford: Oxford University Press.

Douglas M (1975) Implicit Meanings. London: Routledge \& Kegan Paul.

Douglas M (1978) Culture. New York: Russell Sage Foundation.

Drewnowski A \& Greenwood MRC (1983) Cream and sugar: Human preferences for high fat foods. Physiology and Behavior 30, 629-633.

Dugdale AE \& Payne PR (1986) Modelling seasonal changes in energy balance. In Proceedings of the XIIIth International Congress of Nutrition, pp. 141-144 [TG Taylor and NK Jenkins, editors]. London: John Libbey.

Dunbar RIM (1988) Primate Social Systems. London: Croom Helm.

Dunbar RIM (1993) Behavioural adaptation. In Human Adaptation, pp. 73-98 [GA Harrison, editor]. Oxford: Oxford University Press.

Eaton SB \& Konner M (1985) Paleolithic nutrition: A consideration of its nature and current implications. New England Journal of Medicine 312, 283-289.

Ellen R (1982) Environment, Subsistence and System. The Ecology of Small-Scale Social Formations. Cambridge: Cambridge University Press.

Ellis WC, Poppi DP, Matis JH, Lippke H, Hill TM \& Rouquette FM Jr (1999) Dietary-digestive-metabolic interactions determining the nutritive potential of ruminant diets. In Nutritional Ecology of Herbivores, pp. 423-481 [H-JG Jung and GC Fahey Jr, editors]. Savoy, IL: American Society of Animal Science.
Emmans G \& Kyriazakis I (2001) Consequences of genetic change in farm animals on food intake and feeding behaviour. Proceedings of the Nutrition Society 60, 115-125.

Emmans GC \& Oldham JD (1988) Modelling of growth and nutrition in different species. In Modelling of Livestock Production Systems, pp. 13-21 [S. Korver and JAM van Arendonk, editors]. Dordrecht, The Netherlands: Kluwer Academic Publishers.

Feld S (1996) A poetics place: ecological and aesthetic coevolution in a Papua New Guinea rainforest community. In Redefining Nature. Ecology, Culture and Domestication, pp. 61-87 [R Ellen and K Fukui, editors]. Oxford: Berg.

Ferro-Luzzi A \& Branca F (1993) Nutritional seasonality: the dimensions of the problem. In Seasonality and Human Ecology, pp. 149-165 [SJ Ulijaszek and SS Strickland, editors]. Cambridge: Cambridge University Press.

Fiddes N (1991) Meat. A Natural Symbol. London: Routledge.

Fleagle (1999) Primate Adaptation and Evolution. San Diego, CA: Academic Press.

Foley RA (1987) Another Unique Species. Patterns in Human Evolutionary Ecology. Harlow, Essex: Longman Scientific and Technical.

Foley RA (1993) The influence of seasonality on hominid evolution. In Seasonality and Human Ecology, pp. 17-37 [SJ Ulijaszek and SS Strickland, editors]. Cambridge: Cambridge University Press.

Foley RA (1995) Humans Before Humanity. Oxford: Blackwell.

Foley RA \& Lee PC (1991) Ecology and energetics of encephalization in hominid evolution. Philosophical Transactions of the Royal Society of London 334B, 223-232.

Forbes JM (1996) Integration of regulatory signals controlling forage intake in ruminants. Journal of Animal Science 74, 3029-3035.

French SJ (1999) The effects of specific nutrients on the regulation of feeding behaviour in human subjects. Proceedings of the Nutrition Society 58, 533-540.

Galvin KA, Coppock DL \& Leslie PW (1994) Diet, nutrition, and the pastoral strategy. In African Pastoralist Systems: An Integrated Approach, pp. 113-131 [E Fratkin, KA Galvin and EA Roth, editors]. Boulder, CO: Lynne Rienner.

Herman CP \& Mack D (1975) Restrained and unrestrained eating. Journal of Personality 43, 647-660.

Hladik CM (1988) Seasonal variations in food supply for wild primates. In Coping with Uncertainty in Food Supply, pp. 1-25 [I de Garine and GA Harrison, editors]. Oxford: Oxford University Press.

Illius AW \& Jessup NS (1996) Metabolic constraints on voluntary intake in ruminants. Journal of Animal Science $\mathbf{7 4}$ 3052-3062.

Isaac G (1983) Aspects of human evolution. In Evolution from Molecules to Men, pp. 509-544 [S Bendall, editor]. Cambridge: Cambridge University Press.

Isaac G \& Crader D (1981) To what extent were early hominids carnivorous? An archaeological perspective. In Omnivorous Primates, pp. 37-103 [RSO Harding and G Teleki, editors]. New York: Columbia University Press.

Kyriazakis I, Emmans GC \& Taylor AJ (1993) A note on the diets selected by boars given a choice between two foods of different protein concentrations from 44 to $104 \mathrm{~kg}$ liveweights. Animal Production 54, 151-154.

Kyriazakis I, Tolkamp BJ \& Emmans G (1999) Diet selection and animal state: an integrative framework. Proceedings of the Nutrition Society 58, 765-772.

Leonard WR (2000) Human nutritional evolution. In Human Biology. An Evolutionary and Biocultural Perspective, pp. 295-343 [S Stinson, B Bogin, R Huss-Ashmore and D O'Rourke, editors]. New York: Wiley-Liss. 
Leonard WR \& Robertson ML (1994) Evolutionary perspectives on human nutrition: the influence of brain and body size on diet and metabolism. American Journal of Human Biology 6, 77-88.

Leonard WR \& Robertson ML (1997) Rethinking the energetics of bipedality. Current Anthropology 38, 304-309.

Levi-Strauss C (1970) The Raw and the Cooked. London: Cape.

Lewin R (1998) Principles of Human Evolution. Oxford: Blackwell.

Machida H, Perkins E \& Giacometti L (1967) The anatomical and histochemical properties of the tongue of primates. Folia Primatologica 5, 264-279.

Martin RD (1993) Scaling. In The Cambridge Encyclopedia of Human Evolution, p. 42 [S Jones, R Martin and D Pilbeam, editors]. Cambridge: Cambridge University Press.

Mela D (1996) Eating behaviour, food preferences and dietary intake in relation to obesity and body-weight status. Proceedings of the Nutrition Society 55, 803-816.

Mela DJ \& Catt S (1996) Ontogeny of human taste and smell preferences and their implications for food selection. In Long-term Consequences of Early Environment. Growth, Development and the Lifespan Developmental Perspective, pp. 139-154 [CJK Henry and SJ Ulijaszek, editors]. Cambridge: Cambridge University Press.

Milton K (1987) Primate diets and gut morphology: implications for human evolution. In Food and Evolution: Toward a Theory of Human Food Habits, pp. 93-116 [M Harris and EB Ross, editors]. Philadelphia, PA: Temple University Press.

Moore MS (2000) Interactions between physical activity and diet in the regulation of body weight. Proceedings of the Nutrition Society 59, 193-198.

Mori A (1979) An experiment on the relation between the feeding speed and the caloric intake through leaf eating in Japanese monkeys. Primates 20, 185-195.

Nestle M (1999) Animal v. plant foods in human diets and health: is the historical record unequivocal? Proceedings of the Nutrition Society 58, 211-218.

Pelto GH (1987) Social class and diet in contemporary Mexico. In Food and Evolution: Toward a Theory of Human Food Habits, pp. 517-540 [M Harris and EB Ross, editors]. Philadelphia, PA: Temple University Press.

Pitroff W \& Kothmann MM (1999) Regulation of intake and diet selection by herbivores. In Nutritional Ecology of Herbivores, pp. 366-422 [H-JG Jung and GC Fahey Jr, editors]. Savoy, IL: American Society for Animal Science.

Poppitt SD \& Prentice AM (1996) Energy density and its role in the control of food intake: evidence from metabolic and community studies. Appetite 26, 153-174.

Ralph A \& James WPT (1999) New understanding in obesity research. Proceedings of the Nutrition Society 58, 385-393.

Richard AF (1993) Food in a primate's life. In The Cambridge Encyclopedia of Human Evolution, p. 66 [S Jones, R. Martin and D Pilbeam, editors]. Cambridge: Cambridge University Press.

Rolls BJ, Castellanos VH, Halford JC, Kilara A, Panyam D, Pelkman CL, Smith GP \& Thorwart ML (1998) Volume of food consumed affects satiety in men. American Journal of Clinical Nutrition 67, 1170-1177.

Rothwell N \& Stock M (1982) Obesity and Leaness. London: John Libbey.

Schachter S (1971) Some extraordinary facts about obese humans and rats. American Psychologist 26, 129-144.
Schachter S \& Rodin J (1974) Obese Humans and Rats. Washington, DC: Erlbaum/Halsted.

Shetty PS (1993) Chronic undernutrition and metabolic adaptation. Proceedings of the Nutrition Society 52, 267-284.

Shipman P (1983) Early hominid lifestyle: Hunting and gathering or foraging and scavenging. In Animals and Archaeology. vol. 1, Hunters and their Prey. British Archaeological Reports International Series, no.163, pp. 31-49 [J Clutton-Brock and C Grigson, editors]. London: British Archaeological Reports International.

Simmen B \& Hladik CM (1998) Sweet and bitter taste discrimination in primates: scaling effects across species. Folia Primatologica 69, 129-138.

Speth J (1991) Protein selection and avoidance strategies of contemporary and ancestral foragers: unresolved issues. Philosophical Transactions of the Royal Society 334B, 265-270.

Spitzer L \& Rodin J (1981) Human eating behavior: A critical review of studies in normal weight and overweight individuals. Appetite 2, 293-329.

Stringer CB (1993) Evolution of early humans In The Cambridge Encyclopedia of Human Evolution, pp. 241-242 [S Jones, R Martin and D Pilbeam, editors]. Cambridge: Cambridge University Press.

Stubbs J (1998) Appetite, feeding behaviour and energy balance in human subjects. Proceedings of the Nutrition Society 57, 341-356.

Ulijaszek SJ (1991) Human dietary change. Philosophical Transactions of the Royal Society 334B, 271-279.

Ulijaszek SJ (1992) Energetics methods in biological anthropology. Yearbook of Physical Anthropology 35, 215-242.

Ulijaszek SJ (1993) Seasonality of reproductive performance in rural Gambia. In Seasonality and Human Ecology, pp. 17-37 [SJ Ulijaszek and SS Strickland, editors]. Cambridge: Cambridge University Press.

Ulijaszek SJ (1995) Human Energetics in Biological Anthropology. Cambridge: Cambridge University Press.

Ulijaszek SJ (1996) Energetics, adaptation, and adaptability. American Journal of Human Biology 8, 169-182.

Ulijaszek SJ \& Strickland SS (1993) Nutritional Anthropology. Prospects and Perspectives. London: Smith-Gordon.

Vrba ES (1988) Late Pleistocene climatic events and hominid evolution. In Evolutionary History of the 'Robust' Australopithecines, pp. 405-426 [FE Grine, editor]. Hawthorne, NY: Aldine.

Waterlow JC (1986) Notes on the new estimates of energy requirements. Proceedings of the Nutrition Society 45, 351-360.

White TD, Suwa G \& Asfaw B (1994) Australopithecus ramidus, a new species of early hominid from Aramis, Ethiopia. Nature 371, 306-312.

Wiessner P (1996) Introduction: food, status, culture, and nature. In Food and the Status Quest, pp 1-18 [P Wiessner and W Schieffenhovel, editors]. Oxford: Berghahn Books.

Wood B (1994) The oldest hominid yet. Nature 371, 280-281.

Wood B \& Collard M (1999) The human genus. Science 284, 65-71.

Wrangham RW, Jones JH, Laden G, Pilbeam D \& Conklin-Brittain NL (1998) The raw and the stolen. Cooking and the ecology of human origins. Current Anthropology 40, 567-594. 